\title{
ESTUDOS DA ESTRATÉGIA COMO PRÁTICA NA PERSPECTIVA ESTRUTURACIONISTA: EXEMPLO DE CONTRIBUIÇÃO METODOLÓGICA
}

\section{RESUMO}

O artigo descreve o percurso ontológico e metodológico de coleta e análise de dados traçados em uma pesquisa sob os pressupostos da Estratégia como Prática $(S-a s-P)$ na perspectiva Estruturacionista. A investigação recaiu sobre a análise das práticas administrativas na formação de estratégias executadas pelos proprietários e consultores externos (Practitioners) membros do Conselho Consultivo de uma Holding Familiar de Grande Porte. Observando a Ontologia dos Potenciais como elemento do Estruturacionismo optamos por enquadrar a pesquisa na Abordagem Multimodal. Os métodos utilizados foram a Vídeo-etnografia com observação não participante, Entrevistas Abertas em profundidade e não dirigidas, e a Análise Documental. A operacionalização desta estrutura metodológica promoveu à pesquisa a profundidade analítica necessária aos pressupostos teóricos estruturacionistas da Análise da Conduta Estratégica e da Dualidade da Estrutura e, também, garantiram a validade e confiabilidade dos resultados. Destarte, o objetivo principal deste artigo é contribuir para promover futuros estudos da Estratégia como Prática na perspectiva Estruturacionista fornecendo uma estrutura (framework) descritiva detalhada desde os pressupostos ontológicos até a operacionalização das análises.

Palavras-chave: Estratégia como Prática; Teoria Estruturacionista; Holding Familiar; Ontologia; Metodologia; Abordagem Multimodal.

\section{STRATEGY RESEARCHES AS PRACTICE IN VIEW STRUCTURATIONIST: AN EXAMPLE OF METHODOLOGICAL CONTRIBUTION}

\section{ABSTRACT}

The paper describes the ontological and methodological course of data collection and analysis outlined in a research under the assumptions of the Strategy as Practice (S-as-P) in Structurationist perspective. The research portrayed the analysis of administrative practices in formation of strategies executed by the owners and external consultants (Practitioners) members of the Advisory Board in a Family Holding. By observation of Ontology of Potential as Structurationism element we chose to frame the research in the Multimodal Analysis Methodology. The methods used were Video-based ethnography; In-depth Interview; and Documental Content Analysis. The operationalization of this methodology framework promoted to research the analytical depth required to theoretical structurationist assumptions of strategic conduct analysis and the duality of structure and also ensured the validity and reliability of results. Thus, the main objective of this article is to contribute to promote future studies of Strategy as Practice in Structurationist perspective providing a $\mathrm{k}$ detailed descriptive framework since the ontological assumptions to the operationalization of the analysis.

Keywords: Strategy as Practice; Structurationist Theory; Family Holding; Ontology; Methodology; Multimodal Analysis Methodology 
ESTRATEGIA DE INVESTIGACIÓN COMO PRÁCTICA EN VISTA ESTRUCTURACIONISTA: EJEMPLO CONTRIBUCIÓN METODOLÓGICA

\section{RESUMEN}

El artículo describe el enfoque ontológico y metodológico para la recopilación de datos y el análisis se indica en un estudio bajo los supuestos de la estrategia como práctica (S-as-P) en la perspectiva estructuracionista. La investigación cayó en el análisis de las prácticas de gestión en las estrategias de capacitación ejecutados por los propietarios y consultores externos (médicos) de los miembros del Consejo Asesor de la Familia Holding Grande Porte. Observando Ontología del Potencial como elemento Estruturacionismo elegimos para enmarcar la investigación en el Enfoque Multimodal. Los métodos utilizados fueron la etnografía de vídeo con la observación no participante, Open Entrevistas en profundidad y sin dirección, y análisis de documentos. La implementación de este marco metodológico promovido a la investigación de la profundidad analítica necesaria para Análisis supuestos teóricos estruturacionistas de Conducta Estratégica y la dualidad de la estructura y también se aseguró la validez y fiabilidad de los resultados. Por lo tanto, el objetivo principal de este artículo es contribuir a la promoción de los futuros estudios de estrategia como práctica en perspectiva estructuracionista proporcionando un marco (marco) detallada descriptiva ya que los supuestos ontológicos a la puesta en funcionamiento del análisis.

Palabras-clave: Estrategia y Práctica; Teoría estructuracionista; Familia Holding; Ontología; Metodología; Enfoque multimodal.

\footnotetext{
${ }^{1}$ Doutor em Administração pela Universidade Nove de Julho - UNINOVE. Coordenador do curso de Pós-graduação em Gestão Internacional de Negócios - SENAC/Sorocaba. Professor em Administração de Empresas, Comércio Exterior e Relações Internacionais na UNIFIEO. Brasil. E-mail: mlmarietto@uol.com.br

${ }^{2}$ Doutor em Administração pela Universidade de São Paulo - USP. Coordenador do Programa de Pós Graduação em Administração da Universidade Nove de Julho - PPGA/UNINOVE. Brasil. E-mail: maccari@ uninove.br
} 


\section{INTRODUÇÃO}

"A abordagem da Estratégia como Prática requer um olhar muito próximo, detalhado e pormenorizado das atividades dos Practitioners"

(La Ville e Mounoud, 2010, p.183)

Sobre o desafio empírico direcionado a Estratégia como Prática na perspectiva Estruturacionista, ambas inerentes a uma ontologia intersubjetiva que considera a potência dos fatos sociais, Giddens (1984, p.286-287) destacou a importância da pesquisa social ser sensível as habilidades complexas que os atores sociais possuem para coordenar os contextos de seu comportamento cotidiano. Uma vez que, a vida social pode, com frequência, ser previsível em seu curso, esta previsibilidade, em muito de seus aspectos, são os próprios atores sociais que fazem acontecer. Muitas vezes ela não acontece apesar das razões que eles têm para sua conduta. Portanto, solicita-se, também, ao analista social a sensibilidade a constituição espaçotemporal da vida social. Onde, analisar a coordenação espaço-temporal de atividades sociais significa estudar as características contextuais de locais onde os atores sociais se movimentam em seus percursos cotidianos e regionalização de locais que se estendem através do tempo-espaço (Giddens, 1984).

Observando a sensibilidade dos elementos estruturacionistas, Whittington (2007) sugeriu recorrer aos pressupostos ontológicos da Teoria Estruturacionista para a análise da Prática Estratégica nas organizações. A dimensão central do Estruturacionismo é a "Prática", ou seja, a prática social ordenada através do tempo-espaço (Giddens, 1979; 1984). Sua principal argumentação recaiu sobre compreender a atividade dos sujeitos como objetivo central da análise social. Ao desenvolver os conceitos de Agência, Estrutura e Dualidade da Estrutura, Giddens (1979; 1984) conduziu a uma importância intrínseca a investigação da prática da ação estratégica.

A análise da Prática Estratégica, na perspectiva estruturacionista, baseia-se em uma Ontologia Intersubjetiva (Machado-da-Silva, Fonseca e Crubellate, 2005) calcada em uma epistemologia Interpretativa (Giddens, 1984; 1979). Desta forma, os desafios ontológicos de compreensão da realidade organizacional propostos pela Teoria Estruturacionista tornaram a teoria complexa, pois envolvem conceitos e proposições gerais que operam em um alto nível de abstração. A teoria não se conecta facilmente a qualquer método de pesquisa especifico ou abordagem metodológica o que dificulta sua aplicação empírica (Pozzebon e Pinsonneault, 2005).

Mesmo com os desafios metodológicos e a complexidade teórica Whittington (2010) ofereceu diversas sugestões para os estudos da $S$-as- $P$ na perspectiva Estruturacionista. Para a Estratégia como
Prática a Teoria Estruturacionista oferece aos pesquisadores vários elementos atraentes como: a) atenção aos detalhes micro sociológicos; b) sensibilidade ao contexto institucional; e c) abertura à mudança. $\mathrm{O}$ autor também explicou que os pesquisadores da $S$-as- $P$ claramente encontrarão utilidade para a Análise da Conduta Estratégica no fenômeno da Dualidade da Estrutura Organizacional, especialmente para a compreensão do poder de agência dos gestores. Dada à audiência dos pesquisadores da $S$ as- $P$, este fluxo de trabalho tem forte potencial de desenvolver conhecimento para fora do topo hierárquico das organizações podendo envolver consultores e outros atores sociais que lidam com a estratégia nas Organizações.

Apesar dos desafios vinculados ao empirismo da teoria estruturacionista este artigo tem o propósito de incentivar a pesquisa dentro da área da Estratégia Organizacional. Para isto o artigo descreve o percurso ontológico e metodológico de coleta e análise de dados traçados em uma pesquisa sob os pressupostos da Estratégia como Prática $(S-a s-P)$ na perspectiva Estruturacionista. Em suma, a pesquisa buscou conhecer e analisar as práticas administrativas e sociais que ocorrem entre os proprietários e consultores externos (Practitioners) de um Conselho Consultivo Conduta Estratégica (Giddens, 1984, p.288-290) - em inter-relação recursiva com as propriedades estruturais - Dualidade da Estrutura (Giddens, 1984, p.298-299) em uma Holding Familiar de Grande Porte que busca um ajuste administrativo para a sua durabilidade dinâmica. O estudo utilizou a Metodologia Multimodal de Análise (Streeck, Goodwin e LeBaron, 2011). Esta perspectiva permitiu traspassar as dificuldades impostas pela Teoria Estruturacionista de não se acoplar facilmente a qualquer método de pesquisa (Pozzebon e Pinsonneault, 2005).

A Análise da Conduta Estratégica demanda uma observação detalhada e muito próxima do comportamento e dos elementos sociais presentes nas inter-relações entre os atores sociais. Por outro lado, o estudo da Dualidade da Estrutura requer a investigação em diferentes planos de análise espaço-temporais. Para isto empregou-se três métodos de coleta e análise de dados: a) Vídeo-etnografia com observação não participante (LeBaron 2008; Liu e Maitlis, 2014); b) Entrevistas Abertas em Profundidade e não dirigidas (Rubin e Rubin, 2004; Guion, Diehl e McDonald, 2011); e c) Análise Documental (Souza, Kantorski e Villar Luis, 2011). A utilização promoveu à pesquisa a profundidade analítica requerida aos estudos neste tema. Mais do que isto, a combinação de três métodos diferentes possibilitou, também, a triangulação dos dados. Esta convergência entre os métodos (between methods approach - Jick, 1979) fortaleceu a validade e a confiabilidade dos resultados apurados.

Este artigo divide-se na explicação do contexto organizacional da pesquisa. Em seguida adentramos ao 
Design da Pesquisa. Após, fomentamos o Enquadramento do design da pesquisa detalhando a proposição ontológica, epistemológica, metodológica e a descrição da operacionalização dos métodos da pesquisa. Finalmente, estabelecemos as considerações finais buscando contribuir com outras indicações de procedimentos metodológicos estruturacionistas dentro e fora da perspectiva da Estratégia como Prática.

\section{CONTEXTO DA PESQUISA}

O contexto apresentado nesta sessão tem o objetivo de localizar o leitor quanto a Organização e os episódios das reuniões do Conselho Consultivo. Devese ater que a Organização, em si, não foi objeto desta pesquisa, mas a interação entre seus proprietários e membros do conselho consultivo nos episódios de formação das Estratégias para a sobrevivência da Holding. Assim, a intenção empírica deste estudo traduziu-se como uma investigação social de dinâmica longitudinal ocasionada pelas inter-relações entre os atores sociais que se suportaram nas propriedades estruturais do sistema social organizacional vigente. A pesquisa transcorre durante um período, aproximado, de 1 ano (2013 e 2014).

O conselho consultivo da Holding investigada pode ser considerado de grande porte, pois possui um faturamento anual de U\$1BI e, aproximadamente, 6400 funcionários em todo grupo. Sua estrutura operacional compõe-se de fábricas, lojas de varejo e serviços em diversas regiões do país compreendendo uma ampla gama de produtos em diversos setores. Sua caracterização acionária traduz-se em empresa familiar. As famílias possuem representantes no conselho consultivo. Atualmente, uma família possui $70 \%$ das ações do grupo e, também, o presidente do grupo. Isto se deve ao fato de que, além da maior participação acionária, o pai do atual Presidente foi o fundador da organização. Outra família é proprietária dos $30 \%$ das ações e, também, é representada no conselho consultivo pelo vice-presidente.

De acordo com os dados apurados, a Holding, nos últimos anos, "cresceu demais" e iniciou uma demanda de criação de um conselho consultivo para a orientação das estratégias futuras, principalmente, em relação às interações entre os sócios. A instauração do Conselho Consultivo parece ter sido a forma encontrada para esta reorganização. Este conselho passou a atuar junto aos proprietários da empresa buscando proporcionar uma visão externa para mesma. Ou seja, consultores externos, que não fazem parte do Grupo, mas que possuem experiência de mercado e experiência acadêmica, passaram a atuar em meio a reuniões mensais com uma aparente proposta de "oxigenar" a alta direção com novas ideias apontando pontos de melhorias nos negócios. Outra estratégia adotada pelos consultores foi ensinar, por meio de dinâmicas e exercícios, formas de pensar estrategicamente o Grupo voltando-se a durabilidade dinâmica da Holding. Assim, selecionaram-se dois consultores. Um dos consultores é um "conselheiro antigo, já aposentado, de um grande grupo industrial e que fornece apoio consultivo nas questões financeiras". O outro consultor foi indicado por uma consultora de Family Business e tornou-se responsável pelo apoio consultivo relacionado às Estratégias Organizacionais, internas e externas, à empresa visando à durabilidade dinâmica da mesma.

Em suma, o papel do consultor externo em estratégia era o de propor e implantar mudanças na estrutura interna da empresa com o objetivo de um melhor desempenho e sobrevivência da Holding. Estas interações de debates de propostas para formação de Estratégias realizaram-se nas ocasiões das reuniões do conselho consultivo, ou eventualmente, fora das mesmas. Sua função, também, é a de manter ideias, formas e estruturas já presentes na Holding que, de alguma forma, funcionem de maneira adequada aos interesses da mesma.

A tese foi de que os membros do conselho consultivo, tanto consultores como os proprietários do Grupo, já conheciam formas e elementos para montar um Conselho Consultivo. Neste sentido, percebeu-se que as reuniões do conselho consultivo ocorreram sempre de forma estruturada. Ainda que não se possa apurar se estas propriedades estruturais ocorreram de forma voluntaria ou combinada, esta estrutura foi composta pela padronização de acontecimentos nas reuniões.

A respeito destas formas estruturais, a análise longitudinal das atas, a análise dos episódios gravados em áudio e vídeo e a entrevista em profundidade revelaram um padrão de ocorrências factuais nos episódios de reuniões. As reuniões aconteceram sempre na sede do grupo, inclusive, sempre na mesma sala. Havia um intervalo de 1 hora para o almoço, onde foi convencionado pelos membros que não era permitido abordar qualquer assunto sobre o Conselho ou as Reuniões. O ambiente institucional apresentava-se de forma ordenada, onde, verificou-se em todos os 10 episódios a presença comum de 6 participantes: 1) Presidente; 2) Vice presidente da área e sócio minoritário com 30\% das ações; 3) Irmão do presidente e vice-presidente de área e serviços; 4) Cunhado do presidente e vice presidente de área; 5) Consultor Externo Financeiro; e 6) Consultor Externo Estratégico. Ou seja, pode-se inferir que sem a presença de um destes 6 membros as reuniões não aconteciam.

Todas as 10 reuniões observadas começaram sempre com a mesma forma de interação. Com uma apresentação formal do Presidente da Holding dando boas vindas, após com a cobrança do mesmo aos demais membros fixos em relação a aprovação das atas das reuniões passadas e, finalmente, com a apresentação dos resultados mensais, eventualmente, anuais dos números de desempenho financeiro dos diversos negócios da Holding. Estas apresentações eram realizadas pela Controller do grupo em Power 
Point ou outras ferramentas de arquivo eletrônico. Estes números eram apresentados por setores dos negócios do Grupo (comércio, indústria, entre outros) ou pelos negócios individualmente. Um padrão de interação entre alguns membros do conselho nas reuniões foi estabelecido de maneira formal, ou informal.

\section{DESIGN DA PESQUISA}

O estudo foi enquadrado como de natureza descritiva e analítica. Os estudos descritivos e analíticos são usados em diversas áreas das ciências para uma exploração sistemática e profunda do fenômeno/objeto. As ciências sociais, especificamente, as pesquisas em Estratégia Organizacional, buscam nos estudos descritivos e analíticos a profundidade requerida na descrição e análise de fenômenos sociais, seja em nível de sociedade, organizacional, grupos, ou até mesmo indivíduos sociais.

A responsabilidade da pesquisa neste estudo ampara-se nos dizeres de Giddens (1984, p.285), quando enfatiza que as descrições de fenômenos sociológicos têm a tarefa de mediar às redes de significado dentro das quais os atores orientam sua conduta. Estas descrições são categorias interpretativas que pedem, também, um esforço de tradução dentro e fora das redes de significado envolvidas nas teorias sociológicas. Aqui, o cientista é um comunicador, apresentando redes de significado associados com certos contextos da vida social àqueles que estão em outros.

Para descrever e comunicar os fenômenos sociais Creswell (2009) recomenda três elementos fundamentais em um protocolo de pesquisa: visão global da pesquisa; estratégia da pesquisa; e os métodos. Na direção da abordagem de Creswell (2009), a visão global da pesquisa recai sobre o pressuposto ontológico da Intersubjetividade (Machado-da-Silva, Fonseca e Crubellate, 2005) e da Ontologia dos Potenciais (Giddens 1979 e 1984; Cohen 1999). Este pressuposto reside no compartilhamento de significados atribuídos por atores individuais em cada situação social específica garantindo uma objetividade localizada, porque é espaço-temporalmente delimitada, além de ocorrer na potência dos constitutivos da vida social. A intersubjetividade e a Ontologia dos Potenciais demandam uma epistemologia Interpretativa. A Estratégia de Pesquisa é qualitativa e multimodal, sendo os métodos a vídeo-etnografia, entrevistas em profundidade e análise documental.

A figura abaixo apresenta a inter-relação da proposição da empírica deste estudo.

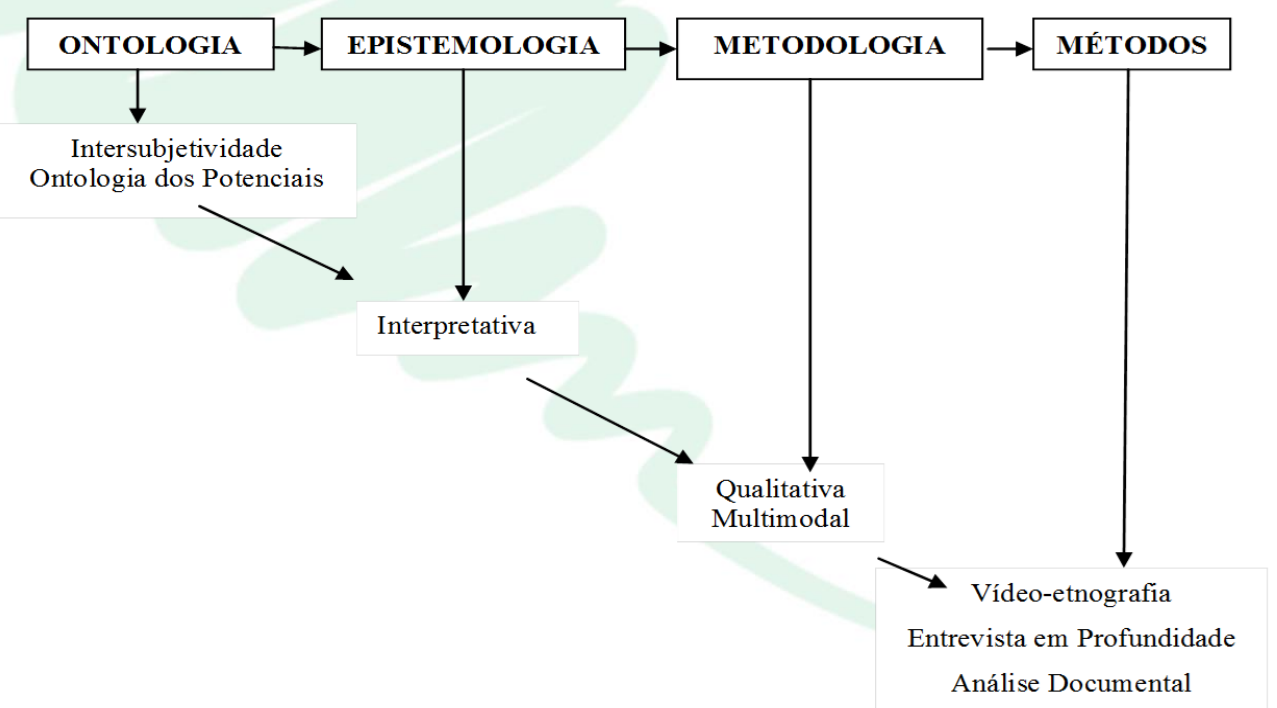

Figura 1: Inter-relação do Design da Pesquisa

Fonte: Adaptado de Grix (2002, p.180)

\section{ENQUADRAMENTO DO DESIGN DA PESQUISA - PROPOSIÇÃOO ONTOLÓGICA, EPISTEMOLÓGICA, METODOLÓGICA E OS MÉTODOS DA PESQUISA}

O estudo baseou-se na apuração dos fenômenos sociais protagonizados por atores sociais (Conselho
Consultivo) imersos no contexto espaço-temporal de formação das Estratégias em uma Holding. A análise dos fenômenos recaiu sobre os pressupostos teóricos e analíticos da Estratégia como Prática na perspectiva Estruturacionista. Assim sendo, julgamos importante delimitar os pressupostos Ontológicos, 
Epistemológicos, Metodológicos e demonstrar os Métodos que fundamentam esta pesquisa.

A clareza Ontológica e Epistemológica nos estudos em ciências sociais deve-se, principalmente, para compreender a inter-relação entre os termos chave da pesquisa. Esta clareza tem por objetivo evitar confusões quando se discute proposições teóricas e abordagens do fenômeno social possibilitando ser capaz de reconhecer outras posições e defender a sua própria posição. Em outras palavras, busca-se evitar conflitos estruturais de pressupostos ontológicos diferentes e, algumas vezes concorrentes ou até antagônicos, relativamente, comuns nas pesquisas sociais, principalmente vinculados a Epistemologias Qualitativas de Pesquisa, sendo que, analogamente, acabam por utilizar ferramentas de pesquisa (métodos) inadequados para o fenômeno em questão (Grix, 2002, p.175-176).

\section{ENQUADRAMENTO ONTOLÓGICO DA PESQUISA}

De forma sintética, Grix (2002, p.177) pontua que para o pesquisador a Ontologia é o ponto de partida para qualquer pesquisa. $\mathrm{O}$ pressuposto ontológico pode ser descrito como a preocupação do que acreditamos que constitui a realidade social. Em outras palavras, as reivindicações e suposições que são feitas sobre a natureza da realidade social, as alegações sobre o que existe, o que isto parece, quais as unidades que o compõem e como essas unidades interagem umas com as outras. Pode ser traduzido como a resposta para a questão: "Qual é a natureza da realidade social $e$ política a ser investigada?"

Este estudo trabalhou com um pressuposto Ontológico Intersubjetivo da realidade social amparada pela Ontologia dos Potenciais. Entende-se aqui que a Intersubjetividade ocorre na Potência do Fenômeno. A apuração do fenômeno, no exato momento e local contextual de seu acontecimento, permite aos atores sociais envolvidos compartilharem seus significados garantindo, assim, a objetividade do fenômeno dentro dos potenciais constitutivos da vida social permitindo a reflexão e interação instantânea sobre os cursos e resultados dos eventos socais gerados (Machado-daSilva, Fonseca e Crubellate, 2005; Cohen 1999; Giddens, 1984).

Um exemplo da relação descrita acima é demonstrado, por meio deste estudo, quando da apuração das inter-relações sociais entre os proprietários e os membros do conselho consultivo que ocorrem nos episódios de reunião para a formação das Estratégias para a durabilidade dinâmica da Holding. As ferramentas de trabalho, os argumentos, as tentativas de influencia, entre outros elementos dos consultores expostas nestes momentos de interação estão carregadas de significados que buscam atingir um objetivo de convencimento sobre os proprietários do negocio em direção aos objetivos de sobrevivência da organização. É neste momento que os proprietários presentes refletem e interagem (capacidade cognoscitiva), por meio da interpretação subjetiva dos significados compartilhados com os consultores objetivando suas ações na busca de intervir, ou não, nos posicionamentos dos consultores tentando direcionar, ou não, os possíveis resultados deste evento. Tentando simplificar, os fenômenos (dados desta pesquisa) serão interpretados no exato contexto momento e local - em que acontecem e com quem os protagoniza (Potência), não existindo a possibilidade de apuração a posteriori.

\section{ENQUADRAMENTO EPISTEMOLÓGICO DA PESQUISA}

Concomitantemente, se a Ontologia é sobre o que pode ser conhecido, então a Epistemologia é sobre "como o que assumimos que existe pode ser conhecido" (Grix, 2002). A Epistemologia como teoria do conhecimento, foca no processo de obter conhecimento especialmente com relação aos métodos, validação e os meios possíveis de se atingir o conhecimento da realidade - independente do entendimento que se tenha a respeito dela. Portanto, a Epistemologia relaciona-se com o desenvolvimento de novos modelos e teorias que são mais adequados do que os modelos e teorias concorrentes. A Epistemologia procura responder: O que e como nós podemos aprender sobre isto? Por quais faculdades atingimos o conhecimento? Para Grix (2002, p.177) há uma clara relação de precedência entre ontologia e epistemologia e metodologia - a ordem é fundamental para compreender os termos.

A Epistemologia aplicada à investigação científica implica em um estudo crítico dos princípios, das hipóteses, das categorias analíticas e dos resultados, determinando sua origem lógica e a sua validade. Portanto, para cada enfoque epistemológico se tem uma maneira especial de conceber os processos lógicos necessários para construir o objeto do conhecimento. A Epistemologia trabalha com a hipótese de que os modelos de investigação se fundamentam em distintas apreciações sobre a relação do objeto e seu contexto. Eles se diferenciam conforme os contornos levados em conta, as formas de delimitar o objeto, isolando-o dos contextos e relacionando-o com eles (Mello, 2005).

O pressuposto epistemológico, também, entende que o todo pode ainda advir da ideia de um resultado. Após a elaboração realizada pelo sujeito num contexto cultural e social específico, e de manifestações de um fenômeno determinado (é uma totalidade que se esconde e que depois se recupera na articulação dos indicadores do fenômeno). Outra forma de compreensão seria o todo como produto da articulação entre os dados objetivos da realidade e a interpretação do sujeito. Na medida em que os fenômenos se articulam, torna-se possível a dinâmica da 
transformação do todo em parte e da parte em todo. Desta forma, um mesmo fenômeno é simultaneamente parte (em relação a um todo mais amplo e complexo) e todo (em relação às partes que o compõem) (Mello, 2005).

De forma sintética, para a apropriação deste todo, entende-se que o debate epistemológico é longo e complexo devido às diversas dimensões epistemológicas dentro da ciência do conhecimento que advogam pela sua primazia. Guerreiro Ramos (1996, p.159), inclusive, pontua que:

É cada vez mais perceptível que as disciplinas academicamente definidas como Economia, Sociologia, Antropologia, Ciência Política, Psicologia Social etc. são diferenciações do saber cientifico decorrentes de um período histórico senão já ultrapassado, em vias de ser superado.

Ou seja, a discussão epistemológica parece ser atemporal e ainda longe de consenso. Contudo, o que interessa é esclarecer ao leitor que existem muitas dimensões epistemológicas em que uma pesquisa pode deitar-se como, por exemplo: Fenomenologia (Husserl, 1990); Materialismo Histórico (Althusser e Badiou, 1986); Positivismo (Comte, 1983), entre outras dimensões. Como postulado em Grix (2002), todo estudo deve possuir uma coerência ontológica, epistemológica e metodológica. Mello (2005), também, esclareceu que esta coerência é mostrada pelo objeto/fenômeno a ser investigado que formará um todo a partir da ideia de um resultado.

Este estudo também possuiu a preocupação de uma coerência epistemológica, porém sabe-se que a teoria de Giddens $(1979 ; 1984)$ é complexa e é atribuída a "Ontologia dos Potenciais constitutivos da vida social". A ausência de hipostatização na Teoria Estruturacionista evita impor quaisquer restrições substantivas aos seus conceitos ontológicos (Cohen, 1999, p.402). Não se postulam "necessidades" universais nem para as coletividades, nem para os atores sociais. Os conceitos não atribuem propriedades "trans-históricas" a práticas ou processos específicos de produção e reprodução social. De tal modo, este posicionamento de Giddens $(1979 ; 1984)$ implica inferir que sua teoria "transcende" a dimensão epistemológica de apreensão do conhecimento a partir da ausência de hipóteses ou proposições. Cohen (1999, p.403) esclareceu, ainda, que tentar uma sistematização da teoria estruturacionista por meio de hipóteses ou proposições seria um "equivoco", uma vez que a teoria trata da produção e reprodução da sociedade pelos agentes sociais e não pelos teóricos sociais. De forma mais simples, tentar sistematizar os processos e os resultados das práxis sociais seria criar uma sistematização trans-histórica, na medida em que conjuntos de proposições ou hipóteses estão sistematicamente correlacionadas em ordem. Esta sistematização contraria o pressuposto que são os agentes sociais, não os teóricos sociais, que produzem, mantem e alteram qualquer grau de "sistemidade" que exista na sociedade (Giddens, 1984, p.165).

Finalmente, este estudo não propôs nenhuma dimensão Epistemológica de investigação. Reservamonos apenas a explicar que adotamos uma perspectiva Epistemológica Interpretativa, porém sem cunhar qualquer dimensão. Esta Perspectiva Interpretativa amparou-se em Giddens (1984) sobre o empirismo na Teoria Estruturacionista (discutido acima) e, também, nos dizeres de Lowenberg (1994), de que a pesquisa interpretativa advém do reconhecimento dos processos interpretativos e cognitivos imersos na vida social.

\section{ENQUADRAMENTO METODOLÓGICO DA PESQUISA}

Este estudo utilizou outra metodologia, que recentemente vem sendo aplicada nos estudos da Estratégia como Prática, que é chamada de Multimodalidade ou Abordagem Multimodal de Pesquisa. A Abordagem Multimodal de pesquisa analisa as interações humanas estabelecendo-se, de maneira mais segura, a inseparabilidade do discurso, artefatos e corpo pela apropriação dos modos de comunicação complementares como a linguagem, gestos, olhares, expressões e mesmo o uso de objetos materiais na atividade social (Streeck, Goodwin e LeBaron, 2011).

O termo Multimodalidade é relativamente novo. Originalmente, foi utilizado nas operações de campo referindo-se ao sistema de transporte multimodal (trem, navio ou caminhão). A carga que partisse de um destino a outro em grandes distancias era transportada por mais de um modal com o objetivo de chegar ao seu destino final, sendo que todas as etapas do transporte são eficientemente ligadas e coordenadas (Boske, 1998). O conceito tem sido usado na pesquisa pósmoderna da semiótica envolvendo combinações de textos, imagens, sons e texturas (eg. Kress e Van Leeuwen, 2001; Norris, 2004) e pela análise do discurso que está especialmente interessado em novas tecnologias de comunicação (eg. Levine e Scollon, 2004).

Cientistas sociais de várias disciplinas tem usado o termo Multimodalidade para examinar a complexidade das interações humanas, como em conversas face a face (eg. Deppermann, 2013). Sabemos, também, de sua recente utilização na área da $S$-as- $P$, Stivers e Sidnell, (2005) e Streeck, Goodwin e LeBaron (2011), já utilizaram a mesma em estudos organizacionais na perspectiva da sócio materialidade (Orlikowski e Scott, 2008). Desta forma, a Multimodalidade parece fornecer meios apropriados para se apurar propostas teóricas interacionistas que consideram a cognição humana imersa, encarnada e distribuída em contextos sociais espaço-temporalmente distribuídos na potencia de seus acontecimentos. Em outras palavras, a abordagem multimodal oferece um 
kit de ferramentas de métodos para traçar as relações entre discurso, artefato e corpo dentro da atividade e da ação humana. Destarte, responde ao desafio de tentar analisar aquilo que é inseparável (Streeck, Goodwin e LeBaron, 2011).

A multimodalidade também fornece uma estrutura analítica que reconhece a diversidade dos recursos semióticos utilizados pelos indivíduos na interação social. Pretendendo levar em conta a forma como esses recursos podem ser orquestrados para construir as atividades e os significados espaço temporais definidos. Os estudos de Estratégia como Prática, cada vez mais reconhecem o papel de artefatos e, em certa medida, o uso corporal no contexto do trabalho estratégico (Jarzabkowski, Spee e Smets, 2012; Vaara e Whittington, 2012). As discussões sobre estratégia e as reuniões são rotineiramente equipadas com flip-charts, quadros brancos e outros dispositivos. As estratégias são muitas vezes feitas por meio da elaboração iterativa de slides em Power Point, onde a mutabilidade dos conjuntos de slides fornece uma plataforma crítica para a interação (Girardeau, 2008; Kaplan, 2011). O papel do corpo tem sido menos explorado. Todavia, Hodgkinson e Wright (2002) conduziram estudos em workshops de estratégia empresarial e observaram como o arranjo dos assentos dos participantes, a dominação física dos CEOs da lousa e das canetas evitou a possibilidade de trabalho colaborativo levando ao fracasso os objetivos do evento como um todo.

Neste estudo, a intenção do uso da Multimodalidade pareceu ser adequada mediante as definições das categorias analíticas da Estratégia como Prática alinhadas a sensibilidade dos pressupostos analíticos da Teoria Estruturacionista, ambos apontados acima. A finalidade foi examinar os episódios sequencias, espaço temporalmente localizados, nas reuniões para formação de estratégias da Holding entre os membros do conselho consultivo. Também, na análise das entrevistas abertas em profundidade com membro do conselho consultivo, além da análise das atas das reuniões. $\mathrm{O}$ objetivo foi capturar a interação e a orquestração da fala (discurso), artefatos (ferramentas) e orientações (corpo) dos atores sociais imersos no contexto técnico-institucional durante os eventos de interação social em planos diferentes $(\mathrm{T} 1+\mathrm{T} 2+\mathrm{T} 3 .$.$) . Foi possível concatenar$ estas diversas formas de análise, o que conferiu ao estudo confiabilidade e rigor necessários na interpretação e análise dos fenômenos apurados na potência de seus acontecimentos.

\section{MÉTODOS DA PESQUISA}

O Método são os conjuntos de técnicas e procedimentos utilizados para a depuração analítica dos dados coletados em campo e pretendem responder a pergunta: "Quão precisos os procedimentos podem ser para adquirir este conhecimento" (Grix, 2002, p.180)? O Método, em si, deve ser visto como livre dos pressupostos ontológicos e epistemológicos e a opção sobre qual deve ser usado deve ser guiada pelas questões de pesquisa. Ainda que, é importante notar que é o pesquisador que utiliza um método particular em um contexto particular, assim, associa-o a um conjunto específico de pressupostos ontológicos. Não é o método que se aproxima do fenômeno ou objeto com uma "bagagem" pré-existente, mas sim o pesquisador. Portanto, uma boa pesquisa não é somente o resultado do uso de um método especifico, mas o resultado de como ele é empregado, como ele é organizado, como ele é checado e triangulado, e como os dados são analisados. A pesquisa deve ser julgada por sua capacidade de constituir uma ligação lógica das partes e não somente por qual método foi utilizado (Grix, 2002).

Naturalmente, algumas pesquisas, como esta, demandam mais de um método. Assim, entende-se que para cada método existem conjuntos de técnicas e procedimentos diferentes para sua execução. Este estudo utilizou os métodos: a) Vídeo-etnografia com observação não participante (LeBaron 2008; Liu e Maitlis, 2014); b) Entrevistas Abertas em Profundidade e não dirigidas (Rubin e Rubin, 2004; Guion, Diehl e McDonald, 2011); e c) Análise Documental (Souza, Kantorski e Villar Luis, 2011).

Pode-se inferir que a vídeo-etnografia proporcionou a análise do micro nível (micro-level) do fenômeno evidenciando os elementos de Conduta Estratégica dos indivíduos imersos contextualmente no Sistema Social da Holding. Enquanto que, a Entrevista em Profundidade e a Análise Documental proporcionaram a ligação com o nível meso (mesolevel) permitindo investigar a relação entre a dinâmica contextual da conduta estratégica dos atores sociais e o fenômeno da Dualidade da Estrutura na Holding proporcionando a ligação longitudinal dos fenômenos. Para um entendimento mais apurado das análises de Micro, Meso e Macro Nível (Level) sugerem-se Goldspink e Kay, (2004) e Mayntz, (2004), entre outros.

Antes de adentrarmos as explicações dos métodos, cabe informar ao leitor que para as análises dos dados, primeiramente, criamos tabelas com designativos contextuais. Estes designativos serviram para um melhor direcionamento e identificação dos atores sociais, contextos produtivos e comerciais da Holding e dos métodos empregados na análise dos fenômenos. 


\begin{tabular}{|l|l|}
\hline PR & Presidente do Conselho \\
\hline VPSM & Vice Presidente de Área e Sócio Minoritário \\
\hline CEF & Consultor Externo Financeiro \\
\hline CEE & Consultor Externo Estratégico \\
\hline IVP & Irmão do Presidente e Vice Presidente de Área \\
\hline CVP & Cunhado do Presidente e Vice Presidente de Área \\
\hline FVP & Filho do Presidente e Vice Presidente de Área \\
\hline OU & Outros Participantes nas Reuniões \\
\hline MLM & Pesquisador/Autor do Estudo \\
\hline
\end{tabular}

Designativos para Produtos, Empresa, Fábrica e/ou Grupo

\begin{tabular}{|l|l|}
\hline $\boldsymbol{X} \boldsymbol{X}$ & Produto \\
\hline $\boldsymbol{X} \boldsymbol{X} \boldsymbol{X}$ & Empresa \\
\hline $\boldsymbol{X} \boldsymbol{X} \boldsymbol{X} \boldsymbol{X}$ & Fábrica e/ou Grupo \\
\hline
\end{tabular}

Designativos para Fonte de Dados

\begin{tabular}{|l|l|}
\hline VD & Vídeo-etnografia \\
\hline EP & Entrevista em Profundidade \\
\hline DOC & Documentos \\
\hline
\end{tabular}

\section{VÍDEO-ETNOGRAFIA}

A vídeo-etnografia, também, é conhecida como "micro etnografia" e seu propósito central é a análise dos detalhes sociais e organizacionais por meio da observação cuidadosa dos "pequenos" momentos da atividade humana (micro comportamento) (LeBaron 2008; Liu e Maitlis, 2014).

Liu e Maitlis (2014, p.206) explicaram que a gravação em vídeo é um método relativamente novo na pesquisa em estratégia, permitindo a captura dos micro comportamentos e interações que são as "coisas" da prática estratégica (Johnson, Langley, Melin e Whittington, 2007). Além disso, este método permite um registro fiel dos dados por muito tempo após o trabalho de campo ser concluído. Ou seja, é possível a análise repetida dos episódios importantes durante a fase de análise de dados (Armstrong e Curran, 2006; LeBaron, 2008).

Outra possibilidade da vídeo-etnografia é a realização gravações em áudio e vídeo sem a participação do pesquisador, exatamente como ocorreu neste estudo. As gravações são analisadas repetidamente e de forma rigorosa com atenção para as falas dos participantes (quem diz o quê, quando e como) e seus comportamentos (a localização relativa, orientação e circulação de pessoas e coisas, entre outros detalhes). As análises de vídeo, ainda, podem ser combinadas com outros tipos de informações, tais como outros dados etnográficos obtidos por meio de observações e entrevistas, documentos, entre outros que, em conjunto, fornecem uma variedade de pontos de vista macro e micro da atividade social e organizacional (LeBaron 2008; Liu e Maitlis, 2014).

Sobre a observação não participante pode-se entender que existe certa "vantagem" para o rigor e confiabilidade da pesquisa. O pesquisador encontra-se fora do ambiente contextual dos acontecimentos minimizando a interferência sobre os atores sociais. Outra vantagem pode ser a relativa facilidade de outros indivíduos poderem realizar as gravações em quaisquer ocasiões devido a atual simplicidade de deslocamento e manuseio dos equipamentos de vídeo e, posteriormente, serem levados ao pesquisador para a análise, o que facilita e diminuem os custos da pesquisa. Não obstante, evita-se o risco de eventual "contaminação" do pesquisador pelo possível clima emocional do evento promovendo, assim, ao pesquisador uma análise isenta dos contextos de ocorrência, uma vez que as gravações tornam o fenômeno atemporal.

Neste estudo realizaram-se duas gravações de áudio e vídeo de duas reuniões formais por um integrante presente em ambas as reuniões que envolveram os proprietários da Holding e o conselho consultivo na sede do grupo. Estas reuniões tinham o único objetivo de debater ações estratégicas de médio e longo prazos para a sobrevivência da Holding. As reuniões foram gravadas com espaço temporal de aproximadamente um mês, sendo que a primeira reunião resultou em 3 horas e 36 minutos de gravação e a segunda reunião em 2 horas e 21 minutos. 
As análises ocorreram em duas etapas de maneira microscópica (LeBaron 2008; Liu e Maitlis, 2014) e são descritas abaixo:

Etapa 1: Todo o conteúdo das gravações foi revisto duas vezes de forma a realizar marcações e categorizações dos trechos que continham atividades humanas e interações julgadas relevantes ao estudo (Streeck e Mehus, 2005; Liu e Maitlis, 2014). Esta primeira etapa demandou mais de 70 horas de análise ao longo de 2 meses.

Etapa 2: Após a marcação e categorização dos pontos de interesse nos filmes retornou-se, especificamente, aos pontos e momentos marcados para uma análise mais apurada e detalhada das interações. Foram analisadas as conversas e as interações entre os indivíduos presentes (Compartilhamento de Significados). A partir das declarações e interações verbais, e às vezes não verbais, deste ou daquele indivíduo buscou-se relacionar as reações dos outros indivíduos presentes ás reuniões. Estas análises permitiram examinar, em detalhes, as Condutas Estratégicas em tempo real (Potência dos acontecimentos) dos membros participantes das reuniões (Intersubjetividade). Estas microanálises, também, permitiram observar as ferramentas, sociais ou artefatos - ("Práticas" na $S$-as$P$ - Marietto e Sanches, 2013; Jarzabkowski e Whittington, 2008; e "Recursos" em Giddens 1984; 1979) utilizadas pelos diversos atores sociais em seus micros contextos de participação nas reuniões que transfiguraram como seus ambientes técnicoinstitucionais de ação. Em outras palavras, as microanálises proporcionaram uma apuração detalhada da Cognoscibilidade, Capacidade e Poder de Agência, Intencionalidade, Compartilhamento de Significados, Motivação, entre outros elementos presente nas Condutas Estratégicas imersas no Sistema Social vigente ao grupo controlador da Holding (Giddens, 1984). As microanálises demandaram 250 horas, aproximadamente, em um período aproximado de cinco meses.

Abaixo alguns exemplos de excertos vídeoetnográficos analisados na pesquisa.

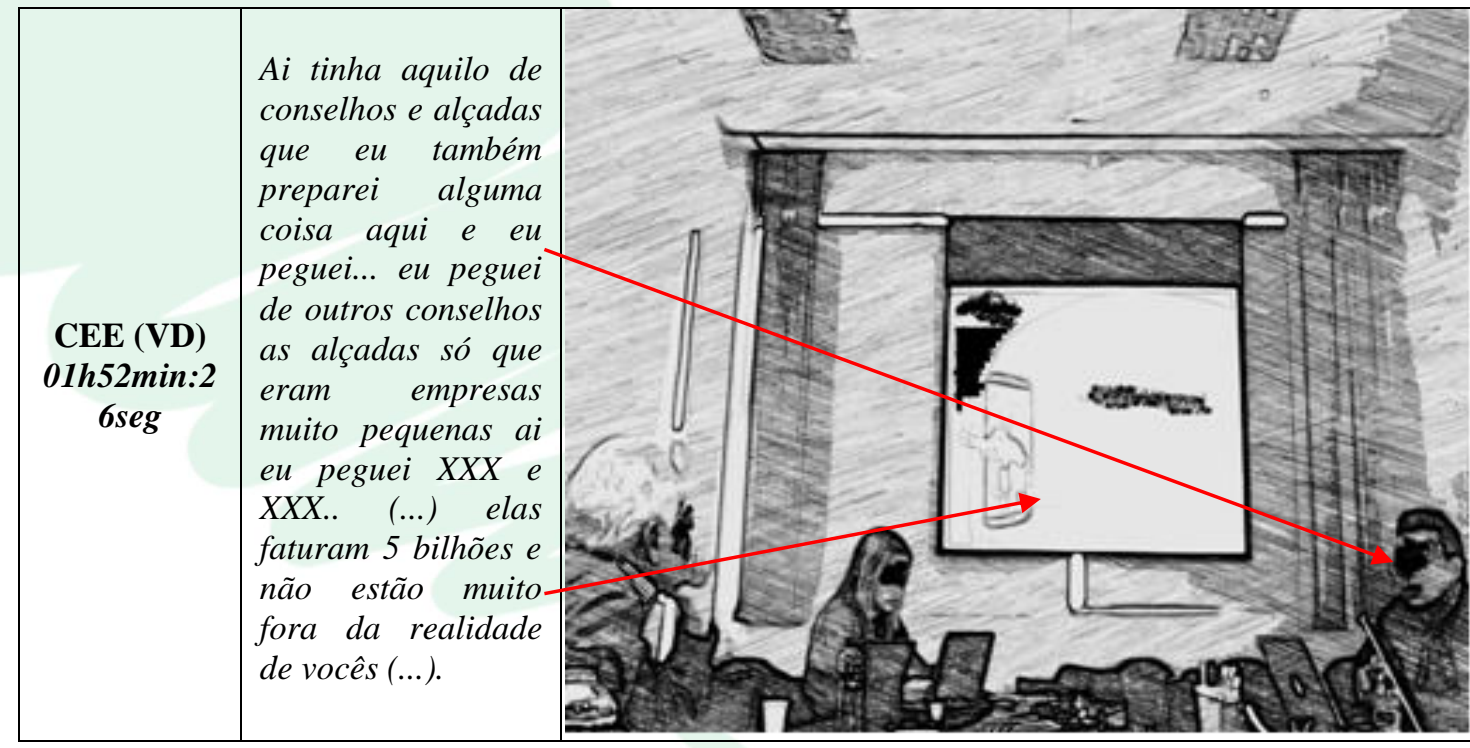




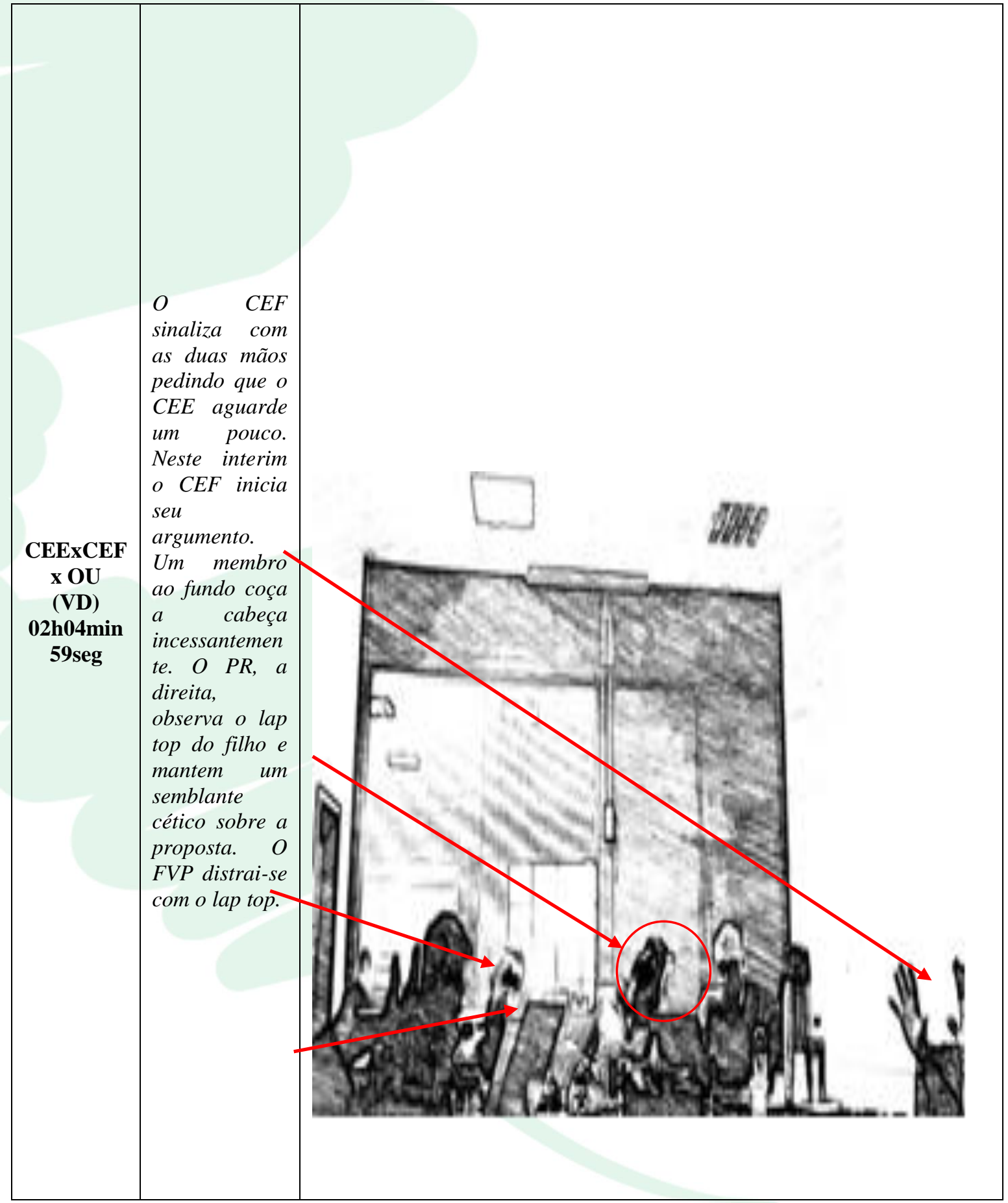

\section{ENTREVISTA EM PROFUNDIDADE}

A Entrevista Qualitativa em Profundidade é, em suma, uma conversa direta e pessoal (que para o leigo pode se aproximar de uma interação cotidiana) buscando-se capturar o universo mental do entrevistado com o objetivo de entender o seu comportamento. É um método aberto, orientado para a descoberta que permite que o entrevistador explore profundamente os sentimentos e perspectivas do entrevistado sobre um assunto. Isso resulta em rica informação de fundo que pode incentivar mais perguntas e descobertas relevantes para o tópico. Em outras palavras, o objetivo da Entrevista em Profundidade não é obter respostas simples, testar hipóteses ou avaliar um conteúdo previamente conhecido, mas entender a experiência "viva" do informante e os significados que este deriva dela. A Entrevista em Profundidade possui caráter aberto pautado por questões iniciais, mas em busca de informações e categorias não previstas pelo entrevistador que torna esse instrumento bastante diferenciado daqueles utilizados em entrevistas 
estruturadas (Suares, Chauvel e Casotti, 2012; Rubin e Rubin, 2004).

O método possui as seguintes características: a) Perguntas abertas que devem ser redigidas de modo que os entrevistados possam discorrer sobre o tema e não apenas responder "sim" ou "não". Muitas perguntas abertas começam com "por que" ou "como", o que dá entrevistados liberdade para responder as perguntas usando suas próprias palavras; b) Possuir um formato Semiestruturado. Conquanto seja importante planejar algumas questões-chave, a entrevista também deve transcorrer por meio da conversação com questões decorrentes de respostas anteriores; c) Buscar compreensão e interpretação utilizando-se de habilidades de escuta ativa para refletir sobre o que o interlocutor está dizendo. O entrevistador deve tentar interpretar o que está sendo dito e deve buscar clareza e compreensão ao longo da entrevista; e d) Registro das respostas ou de toda entrevista gravando-as em áudio e vídeo, sempre que possível, e complementado com notas escritas (notas de campo) pelo entrevistador. As notas escritas devem incluir observações dos comportamentos verbais e não verbais, como eles ocorreram e reflexões pessoais imediatas sobre a entrevista. Em suma, entrevistas em profundidade envolver não só fazer perguntas, mas gravar e documentar sistematicamente as respostas para atingirse um significado e compreensão mais profunda dos fenômenos (Guion, Diehl e McDonald, 2011).

Para esta pesquisa, o principal motivo da utilização da Entrevista em Profundidade amparou-se nos dizeres de Rubin e Rubin (2004, p.3), que explicaram que por meio da Entrevista em Profundidade:

Você pode entender as experiências e reconstruir eventos no qual você não participou. (...) Você pode estender seu alcance intelectual e emocional através dos anos, ocupação, classes, raça, sexo e fronteiras geográficas (...) As entrevistas em profundidade são especialmente adequadas para descrever processos sociais e políticos, que são, como e porque as coisas mudam.

Neste estudo, a Entrevista em Profundidade ocorreu com um dos membros do conselho consultivo. O consultor responsável pelas elaborações das Estratégias no conselho consultivo da Holding. A mesma foi oportuna pela possibilidade de contextualização temporal e factual dos acontecimentos que foram capturados nas gravações de áudio e vídeo das reuniões. Além desta contextualização, a entrevista foi utilizada, de forma paralela, para triangular (Jick, 1979) a veracidade e a confiabilidade dos episódios destacados nas etapas da vídeo-etnografia.

A entrevista teve uma duração de 42 minutos, foi gravada em áudio por meio de um celular. A mesma foi realizada em um ambiente informal (almoço com o entrevistado) em um local de sua escolha com a intenção de "deixar o entrevistado a vontade" para falar o que achar adequado. A entrevista seguiu os rigores descritos acima por (Guion, Diehl e McDonald, 2011) possuindo questões abertas e semiestruturadas. Apesar das perguntas abertas utilizarem muito questões: como, onde, por que, quem, quando, entre outros elementos; por diversas vezes, surgiram perguntas derivadas de respostas do entrevistado que possibilitaram um enquadramento adequado das características longitudinais dos fenômenos reportados.

A análise da entrevista ocorreu, também, de forma microscópica em duas etapas:

Etapa 1: Todo o conteúdo da gravação foi revisto duas vezes de forma a realizar marcações e categorizações dos trechos que continham argumentos que refinavam e complementavam os contextos dos temas e eventos (Rubin e Rubin, 2004; Guion, Diehl e McDonald, 2011). Estas categorizações puderam ser codificadas e inter-relacionadas para a contextualização temporal dos fenômenos, bem como para comprovação de veracidade, ou não, dos episódios destacados por outros indivíduos presentes nas reuniões de Formação das Estratégias da Holding. Esta etapa demandou, em torno de 15 horas de análise.

Etapa 2: Após a marcação e categorização dos pontos de interesse na conversa foi possível retornar, especificamente, aos pontos e momentos destacados na vídeo-etnografia para uma análise mais apurada e detalhada das interações. Desta forma, foi possível concatená-los, interligá-los e interpretá-los atribuindose especificidades temporais e contextuais a episódios que, sem esta análise da entrevista, permaneceriam "soltos" em relação às proposições teóricas da pesquisa. Podemos inferir que, se a etapa de análise da vídeo-etnografia possibilitou a apreensão da Conduta Estratégica dos atores sociais, a etapa de Entrevista em Profundidade e a Análise Documental possibilitaram a apuração, descrição e interação dos elementos componentes do sistema social imerso na Holding (Giddens, 1984; Whittington, 2010). As propriedades estruturais da Holding (Giddens, 1984) também puderam ser observadas e interpretadas. Consequentemente, pode-se aquilatar o fenômeno da Dualidade da Estrutura (Giddens, 1984) na organização mediante a interação dos proprietários e o conselho consultivo da Holding de práticas e ações estratégicas que se reproduziram, ou não, através da Estrutura (Giddens, 1984, p.25) em uma perspectiva longitudinal de durabilidade dinâmica da organização (Rossoni e Machado da Silva, 2008).

Por questões éticas, não foi possível disponibilizar a transcrição da entrevista neste artigo devido ao seu conteúdo sigiloso.

\section{ANÁLISE DE CONTEÚDO DOCUMENTAL}

A Análise Documental é a identificação, verificação e apreciação de documentos para uma finalidade específica. Portanto, preconiza-se a 
utilização de uma fonte paralela e simultânea de informação para complementar os dados e permitir a contextualização das informações obtidas em campo. A Análise Documental deve extrair um reflexo objetivo da fonte original, permitir a localização, identificação, organização e avaliação das informações contidas no documento, além da contextualização dos fatos em determinados momentos tornando-se, assim, um método consistente e estável por lidar com "fontes fixas" de dados e por ser uma técnica que não altera o ambiente ou os sujeitos (Souza, Kantorski e Villar Luis, 2011, p.223).

Bardin (1997) esclareceu que a técnica, também, é considerada como o tratamento do conteúdo com objetivo de apresentá-lo de maneira diferente do original. A Análise Documental pode dar forma e representar de outro modo às informações contidas nos documentos por intermédio de procedimentos de transformação interpretativa. A análise pode proceder visando-se correlacionar os dados dos documentos com outros contextos apurados por meio de outros métodos de pesquisa com objetivo de compreensão mais profunda e detalhada dos objetos/fenômenos pesquisados. Em outras palavras, Patton (2002) e Bardain (1997) concordam que a Análise Documental pode e deve ser usada em caráter complementar a outros métodos de pesquisa qualitativa conferindo maior confiabilidade e rigor na busca de padrões que expliquem os fenômenos observados (Souza, Kantorski e Villar Luis, 2011, p.224).

Como documentos relevantes, esta pesquisa teve acesso a 10 atas de reuniões formais dos proprietários e o conselho consultivo da organização. Estas atas são referentes somente às reuniões de proposta de formação de estratégias com objetivo de durabilidade dinâmica da Holding. As atas traduzem um tempo de, aproximadamente, um ano, onde eventualmente, existiram meses em que foram realizadas mais de uma reunião e outros meses em que as mesmas não aconteceram. Outros documentos que foram fornecidos são as apresentações de Power Point usadas pelo consultor responsável pelo desenvolvimento das estratégias da organização nas reuniões. Os seis arquivos de Power Point recebidos, também, retratam o desenvolvimento longitudinal das reuniões e proporcionaram a possibilidade de comparar e esquematizar os detalhes que foram selecionados nas outras análises desta pesquisa, novamente, possibilitando e assegurando o recorte longitudinal dos fenômenos.

Finalmente, também consideramos como documentos os diversos e-mails trocados entre o pesquisador deste estudo e o membro do conselho consultivo responsável pelo direcionamento estratégico. Estes e-mails foram de vital importância para se contextualizar detalhes e dúvidas que surgiram durante todo o processo analítico do estudo, embora não receberam o mesmo tratamento analítico das atas e dos arquivos de Power Point, pois possuíam um caráter e uma linguagem informal em detrimento aos outros documentos, além de serem mais pontuais e direcionados exatamente a pontos relevantes das análises.

A análise destes documentos ocorreu por meio da apuração e organização do material baseando-se nas leituras sucessivas e sistemáticas dos mesmos. Utilizamos critérios analíticos direcionados aos pressupostos teóricos deste estudo para a caracterização, descrição, levantamento de assuntos recorrentes, codificação, interpretação e inferências (quando necessárias). Os parágrafos dos documentos que descreviam alguma ação realizada, preconizada ou instituída como relevantes ao contexto da pesquisa foram destacados. Foi realizada, então, uma releitura desses parágrafos destacados e foram organizados em uma matriz de relevância e convergência com os assuntos pontuados nas análises. Elencaram-se 13 assuntos relevantes. Esta matriz obedeceu ao caráter temporal das reuniões e foram avaliadas em todas as reuniões as frequências dos assuntos e, também, a intensidade dada ao tratamento destes assuntos. Esta intensidade foi apurada em um escala de 1 a 5 graus, onde 1 para menor intensidade de debate e 5 para uma maior intensidade. Quando o assunto não foi tratado na reunião em questão foi acentuado com 0 na escala. Para medir esta intensidade utilizou-se a técnica de contagem de palavras repetidas provenientes ao assunto e o espaço físico desprendido na ata para o mesmo. Por exemplo, no item elencado como "Ausência de Planejamento Estratégico" contou-se quantas vezes a palavra "Planejamento Estratégico", ou "Planejamento", ou "Estratégia" foi disponibilizada na ata e, também, qual espaço na ata foi utilizado (eg: 3 páginas das 7 que compõem a ata). Finalmente, realizamos a somatória dos graus atribuídos e reorganizamos a classificação dos assuntos levando em consideração a maior pontuação atribuída à somatória. Os resultados estão demonstrados na Tabela abaixo

Os critérios para inclusão das ações ou descrições destacadas, para o contraste e cruzamento com os resultados obtidos nas análises dos outros métodos deste estudo, pautaram-se nas evidências descritas nos documentos, bem como na matriz de análise de documentos que permitiram obter a compreensão dos elementos presentes na Conduta Estratégica e na Dualidade da Estrutura (Giddens, 1984). A característica temporal dos documentos foi fundamental para evidenciar e verificar a veracidade de alguns fatos destacados nas etapas de vídeo-etnografia e entrevista em profundidade do estudo. Em outras palavras, as análises dos documentos serviram de fonte de dados e, ao mesmo tempo, fontes de verificação e triangulação dos dados proporcionando rigor e confiabilidade á pesquisa. 
Matriz de Classificação da Análise de Conteúdo das Atas das Reuniões

\begin{tabular}{|c|c|c|c|c|c|c|c|c|c|c|c|c|}
\hline Temas/Linha do Tempo (Atas) & nov/13 & jan/14 & fev/14 & $\operatorname{mar} / 14$ & abr/14 & $\mathrm{mai} / 14$ & $\mathrm{jul} / 14$ & jul/142 & ago/14 & set/14 & Somatória & $\begin{array}{l}\text { Classificação } \\
\text { Acima de } 25\end{array}$ \\
\hline Apresentação de Resultados & 5 & 5 & 5 & 5 & 5 & 5 & 5 & 5 & 5 & 5 & 50 & $1^{\circ}$ \\
\hline Ausência de PE & 3 & 4 & 5 & 0 & 4 & 3 & 5 & 5 & 4 & 4 & 37 & $2^{\circ}$ \\
\hline Riscos a Holding & 3 & 4 & 4 & 4 & 3 & 0 & 4 & 4 & 3 & 4 & 33 & $3^{\circ}$ \\
\hline Contrapontos entre VPSM e CEE & 0 & 4 & 5 & 5 & 5 & 3 & 3 & 4 & 1 & 3 & 33 & $3^{\circ}$ \\
\hline Problemas com XXXT & 4 & 5 & 3 & 2 & 2 & 4 & 2 & 4 & 1 & 4 & 31 & $4^{\circ}$ \\
\hline Sinergia nos Negócios & 3 & 1 & 4 & 1 & 2 & 4 & 4 & 3 & 3 & 5 & 30 & $5^{\circ}$ \\
\hline Incorporaçào das Famílias & 3 & 0 & 0 & 0 & 0 & 1 & 0 & 0 & 0 & 0 & 4 & \\
\hline Debate sobre Resultados outra Consult & 0 & 4 & 4 & 5 & 0 & 0 & 0 & 0 & 0 & 0 & 13 & \\
\hline Debate sobre Código de Ética & 2 & 3 & 4 & 0 & 0 & 0 & 0 & 0 & 0 & 0 & 9 & \\
\hline Questionamento sobre atuação da XXXA & 0 & 4 & 0 & 3 & 4 & 3 & 3 & 2 & 0 & 0 & 19 & \\
\hline Implantaçào SAP & 3 & 1 & 3 & 0 & 3 & 1 & 0 & 0 & 1 & 1 & 13 & \\
\hline Organograma & 0 & 0 & 0 & 0 & 5 & 3 & 2 & 2 & 4 & 4 & 20 & \\
\hline Compra de Novo Negócio em SC & & & & & & & & & 5 & 4 & 9 & \\
\hline
\end{tabular}

\section{CONSIDERAÇÕES FINAIS}

Este artigo tem como objetivo contribuir para promoção de futuros estudos da Estratégia como Prática na perspectiva Estruturacionista fornecendo uma estrutura (framework) descritiva e detalhada do percurso ontológico e metodológico traçados em uma pesquisa em uma Holding familiar de grande porte. A demonstração da operacionalização metodológica também teve a intenção de demonstrar o rigor e a confiabilidade dos resultados apurados por meio da utilização dos métodos de pesquisa descritos acima. Entendemos que, além de necessários para a apuração minuciosa dos fenômenos, a convergência entre os métodos (between methods approach - Jick, 1979) fortaleceu a validade e a confiabilidade dos resultados apurados. Esta concatenação entre os procedimentos buscou evitar vieses muitas vezes encontrados em pesquisas qualitativas, consequentemente, conferiram rigor às conclusões.

Dito isto, concluímos que o percurso metodológico adotado foi complexo e trabalhoso. Porém, contribuiu, de forma central, para a compreensão pormenorizada de como as atividades dos Practitioners influenciaram, e foram influenciadas, pela ligação entre instituição e ação de seus atores sociais nos eventos de formação das estratégias. A utilização destes procedimentos empíricos revelaram elementos sociais e institucionais, muitas vezes ignorados ou desconhecidos pelos pesquisadores e gestores, mas de fundamental importância para o entendimento das características de mudanças sociais, administrativas e estruturais na condução estratégica das organizações.

Com a descrição desta estrutura (framework) metodológica esperamos incentivar as pesquisas futuras na área da Estratégia como Prática direcionadas aos fenômenos da análise da Conduta Estratégica e da Dualidade da Estrutura. As descrições dos procedimentos executados, naturalmente, figuram como uma sugestão de operacionalização empírica. Sabemos que existem outros procedimentos metodológicos disponíveis que se enquadram na Estratégia como Prática na perspectiva Estruturacionista, além dos pressupostos da análise da conduta estratégica e da dualidade da estrutura. Whittington (2010, p.119) sumariza oito estudos empíricos extraídos de Journals Americanos e Europeus que utilizaram, de forma substancial, as noções Giddens dentro da tradição da $S$-as- $P$ revelando, assim, alguns pressupostos Estruturacionistas e seus procedimentos metodológicos já conectados com a $S$-as- $P$. 
Giddens no Estudo da Prática Estratégica

\begin{tabular}{|c|c|c|c|c|}
\hline AUTORES & TEMA & MÉTODOS & $\begin{array}{l}\text { USO DA TEORIA } \\
\text { ESTRUTURACIONISTA }\end{array}$ & $\begin{array}{c}\text { TEORIAS } \\
\text { ADICIONAIS }\end{array}$ \\
\hline $\begin{array}{c}\text { Balogun e } \\
\text { Johnson (2005), } \\
\text { Org. Studies }\end{array}$ & $\begin{array}{c}\text { Resultados } \\
\text { Intencionais e } \\
\text { interpretações dos } \\
\text { gerentes nas } \\
\text { estratégias de } \\
\text { mudança }\end{array}$ & $\begin{array}{c}\text { Estudo de } \\
\text { Caso: Revisão } \\
\text { de encontros e } \\
\text { anotações }\end{array}$ & $\begin{array}{l}\text { Agência, Significados e } \\
\text { dialética do controle }\end{array}$ & Sensemaking \\
\hline $\begin{array}{c}\text { Howard- } \\
\text { Grenville (2007), } \\
\text { Org. Sci. } \\
\end{array}$ & $\begin{array}{c}\text { Assuntos de Vendas } \\
\text { ao longo do tempo - } \\
\text { Gerentes Médios } \\
\end{array}$ & $\begin{array}{l}\text { Etnografia e } \\
\text { Observação } \\
\text { Participante } \\
\end{array}$ & $\begin{array}{c}\text { Normas, rotinas e } \\
\text { esquemas reproduzidos } \\
\text { através da prática } \\
\end{array}$ & $\begin{array}{c}\text { Politicas } \\
\text { Organizacionais e } \\
\text { Recursos } \\
\end{array}$ \\
\hline $\begin{array}{l}\text { Jarzabkowski } \\
(2008), \text { AMJ }\end{array}$ & $\begin{array}{c}\text { Tipos de } \\
\text { Strategizing, } \\
\text { comportamento e } \\
\text { seus efeitos }\end{array}$ & $\begin{array}{c}\text { Estudo de } \\
\text { Caso } \\
\text { Comparativo: } \\
\text { Entrevistas e } \\
\text { Observações }\end{array}$ & $\begin{array}{c}\text { Estrutura e Agência; } \\
\text { Recursividade e Mudança }\end{array}$ & $\begin{array}{c}\text { Teoria } \\
\text { Institucional }\end{array}$ \\
\hline $\begin{array}{l}\text { Kaplan (2008), } \\
\text { Org. Sci. }\end{array}$ & $\begin{array}{l}\text { Enquadramento de } \\
\text { projetos rivais por } \\
\text { gerentes médios }\end{array}$ & $\begin{array}{l}\text { Observação, } \\
\text { Entrevistas e } \\
\text { Documentos }\end{array}$ & $\begin{array}{l}\text { Poder e habilidade dos } \\
\text { atores }\end{array}$ & $\begin{array}{l}\text { Goffmanesque } \\
\text { Frame Theory }\end{array}$ \\
\hline $\begin{array}{l}\text { Mantere (2008), } \\
\text { JMS }\end{array}$ & $\begin{array}{c}\text { Expectativa sobre as } \\
\text { Estratégias dos } \\
\text { Gerentes Médios } \\
\end{array}$ & $\begin{array}{c}\text { Entrevistas em } \\
12 \\
\text { Organizações } \\
\end{array}$ & Agência e cognoscibilidade & $\begin{array}{c}\text { Middle Manager } \\
\text { Roles }\end{array}$ \\
\hline $\begin{array}{c}\text { Paroutis e } \\
\text { Pettigrew (2007), } \\
\text { Human Relat }\end{array}$ & $\begin{array}{l}\text { Atividades de Times } \\
\text { Estratégicos no } \\
\text { Centro e Periferia }\end{array}$ & $\begin{array}{c}\text { Estudo de } \\
\text { Caso: } \\
\text { Entrevistas }\end{array}$ & $\begin{array}{c}\text { Natureza Rotineira da } \\
\text { Prática e cognoscibilidade } \\
\text { dos agentes }\end{array}$ & $\begin{array}{c}\text { Processo } \\
\text { Estratégico }\end{array}$ \\
\hline $\begin{array}{l}\text { Salvato (2003), } \\
\text { JMS }\end{array}$ & $\begin{array}{l}\text { Micro Estratégias na } \\
\text { evolução da } \\
\text { empresa }\end{array}$ & $\begin{array}{c}\text { Estudo de } \\
\text { Caso } \\
\text { Comparativo: } \\
\text { Entrevistas }\end{array}$ & $\begin{array}{l}\text { Agencia e rotinas de } \\
\text { adaptação }\end{array}$ & $\begin{array}{c}\text { Dynamic } \\
\text { capabilities; } \\
\text { Sewell (1992) }\end{array}$ \\
\hline $\begin{array}{l}\text { Rouleau (2005), } \\
\text { JMS }\end{array}$ & $\begin{array}{l}\text { Gerencia média } \\
\text { interpretando e } \\
\text { vendendo a } \\
\text { mudança }\end{array}$ & $\begin{array}{l}\text { Estudo de } \\
\text { Caso: } \\
\text { Etnografia }\end{array}$ & $\begin{array}{c}\text { Consciência Prática e } \\
\text { Discursiva; Estruturas } \\
\text { Sociais }\end{array}$ & $\begin{array}{l}\text { Sensemaking e } \\
\text { Sensegiving }\end{array}$ \\
\hline
\end{tabular}

Fonte: Whittington (2010, p.119).

Temos ciência, também, que a Teoria Estruturacionista serviu de base analítica em diversos estudos fora da abordagem da Estratégia como Prática. Estes estudos, também, se concentram no nível micro do comportamento estratégico (Whittington, 1992; Pozzebon, 2004). Os mesmos utilizaram propostas metodológicas diferentes destas aqui descritas. Para incentivar o conhecimento e aplicação de outros procedimentos metodológicos dentro da perspectiva estruturacionista sugerimos observar: Rossoni, Marietto e Silva (2011) na Análise de Sistemas Mundiais; Busco (2009) na Administração Contábil Pública; Chiasson e Saunders (2005) no Empreendedorismo; Feldman (2004) em Processos de Mudança Organizacional; Heracleous e Barrett (2001) em Tecnologia de Informação; Orlikowski (2000) em Gestão da Informação em TI; e o mais famoso estudo
Organizacional Estruturacionista, Barley (1986), na implantação de novas tecnologias de diagnóstico por imagens em hospitais na Inglaterra, entre tantos outros.

\section{REFERÊNCIAS}

Althusser, L.; Badiou, A. (1986). Materialismo histórico e materialismo dialético. São Paulo: Global.

Armstrong, V.; Curran. S. (2006). Developing a collaborative model of research using digital video. Computers and Education, v.46, p 336-347. 
Bardin, L. (1997). Análise de conteúdo. Lisboa: Edições 70.

Barley, S. R. (1986). Technology as an occasion for structuring: Evidence from observations of ct scanners and the social order of radiology departments. Administrative Science Quarterly, v.31, n.1, p.78-108.

Boske, L. B. (1998). Multimodal/intermodal transportation in the United States, Western Europe, and Latin America: Governmental policies, plans and programs. Policy Research Report n.130. Austin: Johnson School of Public Affairs.

Busco, C. (2009). Giddens' structuration theory and its implications for management accounting research. Journal of Management and Governance, v.13, n.3, p.249-260.

Chiasson, M.; Saunders, C. (2005). Reconciling diverse approaches to opportunity research using the structuration theory. Journal of Business Venturing, v.20, n.6, p.747-767.

Cohen, I. (1999). Teoria da estruturação e práxis social. In: Giddens, A.; Turner, J. (Org) Teoria social hoje. São Paulo: UNESP.

Comte, A. (1983). Discurso preliminar sobre o conjunto do positivismo. São Paulo: Abril Cultural.

Creswell, J. W. (2009). Research design: Qualitative, quantitative and mixed methods approaches. Thousand Oaks, CA: SAGE Publications, Inc.

Deppermann, A. (2013). Multimodal interaction from a conversation analytic perspective. Journal of Pragmatics, v.46, n.1, p.1-7.

Feldman, M. S. (2004) Resources in emerging structures and processes of change. Organization Science, v.15, n.3, p.295-309.

Giddens, A. (1984). The constitution of society. Berkeley: University of California Press.

Giddens, A. (1979) Central problems in social theory: Action, structure and contradiction in social analysis. Berkeley: University of California Press.

Giraudeau, M. (2008). The drafts of strategy: opening up plans and their uses. Long Range Planning, v.41, n.3, pp.291-308.

Goldspink, C.; Kay, R. (2004). Bridging the micromacro divide: A new basis for social science. Human Relations, v.57, n.5, pp.597-618.
Grix, J. (2002). Introducing Students to the Generic Terminology of Social Research. Political Studies Association, Oxford, v.22, n.3, p.175-186.

Guerreiro Ramos, A. (1996). Situação atual da sociologia. In: A redução sociológica. 3.ed. Rio de Janeiro: Editora da UFRJ.

Guion, L. A.; Diehl, D. C.; Mcdonald, D. (2011). Conducting an in-depth interview. Florida Cooperative Extension Service: University of Florida.

Heracleous, L. Barrett, M. (2001) Organizational change as discourse: Communicative actions and deep structures in the context of information technology implementation. Academy of Management Journal, v.44, n.4, p.755-778.

Hodgkinson, G.; Wright, G. (2002). Confronting strategic inertia in a top management team: Learning from failure. Organization Studies, v.23, p.949-977.

Husserl, E. (1990). A ideia da fenomenologia. Lisboa: Edições 70.

Jarzabkowski, P. Whittington, R. (2008). Directions for a troubled discipline: Strategy research, teaching, and practice introduction to the dialog. Journal of Management Inquiry, v.17 n.4, pp.266-268.

Jarzabkowski, P.; Spee, P.; Smets, M. (2012). Material artifacts: Practices for doing strategy with stuff. European Management Journal, v.31, n.1, p.41-54.

Jick, T. D. (1979). Mixing Qualitative and Quantitative Methods: Triangulation in Action. Administrative Science Quarterly, v.24, n.4, p. 602-611.

Johnson, G.; Langley, A.; Melin, L.; Whittington, R. (2007). Doing research on doing strategy. In: Johnson, G.; Langley, A.; Melin, L.; Whittington, R. Strategy as practice: research directions and resources. Cambridge, UK: Cambridge University Press.

Kaplan, S. (2011). Strategy and PowerPoint: An inquiry into the epistemic culture and machinery of strategy making. Organization Science, v.22, n.2, p.320-346.

Kress, G.; Van Leeuwen, T. (2001). Multimodal discourse: The modes and media of contemporary communication. London: Arnold.

La Ville, V.; Mounoud, E. (2010). A narrative approach to Strategy as Practice: strategy making from texts and narratives. In: Golsorkhi, D.; Rouleau, L.; Seidl, D.; Vaara, E. Cambridge 
handbook of strategy-as-practice. UK: Cambridge University Press.

LeBaron, C. (2008). Video-Based methods for research on strategy as practice: Looking at people, places and things. Key Note Presented at the Professional Development Workshop: Strategy as Practice: Methodological Challenges. In: Anaheim: Academy of Management Meeting.

Levine, P.; Scollon, R. (Eds) (2004). Discourse and technology: Multimodal discourse analysis. Washington, DC: Georgetown University Press.

Liu, F.; Maitlis, S. (2014). Emotional dynamics and strategizing processes: a study of strategic conversations in top team meetings. Journal of Management Studies, v.51, n.2, p.202-234.

Lowenberg, J. S. (1993). Interpretative research methodology: broadening the dialogue. Adv.Nurs.Sc., v.16, n.2, p.57-69.

Machado-da-Silva, C. L.; Fonseca, V. S. Crubellate, J. M. (2005). Estrutura, agência e interpretação: Elementos para uma abordagem recursiva do processo de institucionalização. RAC, Edição Especial, p.09-39.

Marietto, M. L.; Sanches, C. (2013). Strategy as Practice: A study of the practices of strategic action in the SMEs store cluster. International Journal of Management \& Information Technology, v.4, v.1, p.156-165.

Mello, T. A. (2005). Epistemologia e pesquisa em educação. In: Resenha: Fundamentos para la investigacion: Pressupuestos epistemológicos que orientan al investigador. Faculdade de Educação. Campinas: Universidade Estadual de Campinas.

Norris, S. (2004). Analyzing multimodal interaction: A methodological framework. London: Routledge.

Orlikowski, W. J. (2000). Using technology and constituting structures: A practice lens for studying technology in organizations. Organization Science, v.11, n.4, pp.404-428.

Orlikowski, W. J.; Scott, S. (2008). Sociomateriality: Challenging the separation of technology, work and organization. The Academy of Management Annals, v.2, n.1, p.433-474.

Patton, M. Q. (2002). Qualitative research and evaluation methods. 3.ed. Thousand Oaks, California: Sage Publications.
Pozzebon, M. (2004). The influence of a structurationist view on strategic management research. Journal of Management Studies, v.41, n.2, p.247-272.

Pozzebon, M.; Pinsonneault, A. (2005). Challenges in conducting empirical work using structuration theory: Learning from IT research. Organization Studies, v.26, n.9, p.1353-1376.

Rossoni, L.; Marietto, M. L.; Silva, W. V. (2011). The effect of positioning in the world economic system on economic and social development: A relational approach to services. African Journal of Business Management, v.5, n.20, pp.8008-8024.

Rossoni, L.; Machado-da-Silva, C. L. (2008). Análise Institucional da Construção do Conhecimento Científico em Mundos Pequenos. Faces Journal, v.7, n.1. p.25-43.

Rubin, H. J.; Rubin, I. S. (2004). Qualitative interviewing: the art of hearing data. 2.ed. California: Thousand Oaks.

Souza, J.; Kantorski, L. P.; Villar Luis, M. A. (2011). Análise documental e observação participante na pesquisa em saúde mental. Revista Baiana de Enfermagem, v.25, n.2, p. 221-228.

Stivers, T.; Sidnell, J. (2005). Multi-modal interaction. Semiotica, v.156, n.1, p.1-20.

Streeck, J.; Goodwin, C.; Lebaron, C. (Eds) (2011). Embodied interaction: Language and body in the material world. Cambridge: Cambridge University Press.

Streeck, J.; Mehus, S. (2005). Microethnography: The study of practices. In: Fitch K. L. R.; Sanders, E.; (Eds.) Handbook of language and social interaction. Mahwah, NJ: Lawrence Erlbaum.

Suares, M.; Chauvel, M.; A. Casotti, L.; (2012). Motivações e significados do abandono de categoria: Aprendizado a partir da investigação com ex-fumantes e ex-proprietários de automóveis. $\mathrm{Cad}$. EBAPE.BR, v.10, n.2, pp.411-434.

Vaara, E.; Whittington, R. (2012). Strategy as practice: Taking practices seriously. Academy of Management Annals, v.7, n.1, p.285-336.

Whittington, R. (2010). Giddens, structuration theory and strategy-as-practice. In: Golsorkhi, D.; Rouleau, L.; Seidl, D.; Vaara, E. Cambridge handbook of strategy-as-practice. UK: Cambridge University Press. 
Estudos da Estratégia como Prática na Perspectiva Estruturacionista: Exemplo de Contribuição Metodológica

Whittington, R. (2007). Strategy practice and strategy process: Family differences and the sociological eye. Organization Studies, v.28, n.10, p.1575-1586.
Whittington, R. (1992).Putting Giddens into action: Social systems and managerial agency. Journal of Management Studies, v.29, n.6, p.693-712. 